\title{
Ultrasonic monitoring of fetal respiratory movement
}

\author{
R N TREMEWAN, D R AICKIN, J J TAIT
}

British Medical fournal, 1976, 1, 1434-1435

\section{Summary}

Ultrasonic monitoring of fetal respiratory movement including velocity measurements is described. Both proximal and distal walls of the fetal chest are imaged simultaneously. The time-position mode clearly defines fetal respiratory movement and rejects artefacts.

\section{Introduction}

The monitoring of fetal respiratory movement in utero using ultrasound was originally described by Boddy and Robinson. ${ }^{1}$ The fetal heart was detected with the A-scan technique, and the chest-wall echo proximal to the heart echo was selected. The displacement of this echo was observed on a chart recorder. Subsequent workers ${ }^{2}{ }^{3}$ have continued to observe the position of an echo from just one side of the chest. Without observing both proximal and distal walls of the fetal chest, however, simple translational movement of the fetus cannot adequately be distinguished from respiratory movement.

\section{Technique}

A diagnostic pulsed ultrasonic machine (Diasonograph NE 4102) with modifications ${ }^{4}$ to provide a chart recording of target position and velocity is used. The fetal chest is first imaged using the section scan

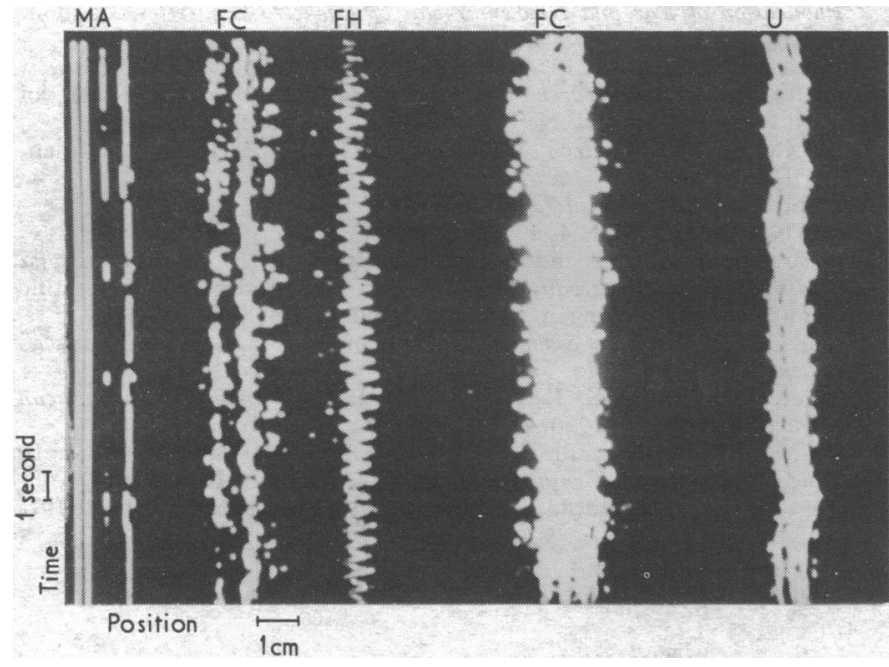

FIG 1-Time-position image of fetal respiratory movement. Movement of the fetal chest walls (FC) can be seen. Other structures are shown: maternal abdomen (MA), fetal heart (FH), and posterior uterine wall (U).

University Department of Obstetrics and Gynaecology, Christchurch Women's Hospital, Christchurch, New Zealand.

D R AICKIN, MD, MRCOG, professor of obstetrics and gynaecology

R N TREMEWAN, BSC, ME, medical student

Department of Medical Physics, Christchurch Hospital, Christchurch, New Zealand

J J TAIT, MSC, MIERE, chief physicist mode (compound B-scan) to produce the conventional ultrasonic tomogram. The ultrasonic beam is then appropriately aligned through the fetal chest. Either the proximal or distal chest wall echo is selected from the A-scan and its position and velocity is recorded on a two channel Astro-Med 202 chart recorder. At the same time all echoes are displayed using the time-position mode ( $\mathrm{M}$-mode) of the Diasonograph, which provides the definitive information on the nature of the chest wall movement.

Fig 1 is a time-position recording illustrating respiratory movement of a fetal chest near term and also showing the fetal heart movement.

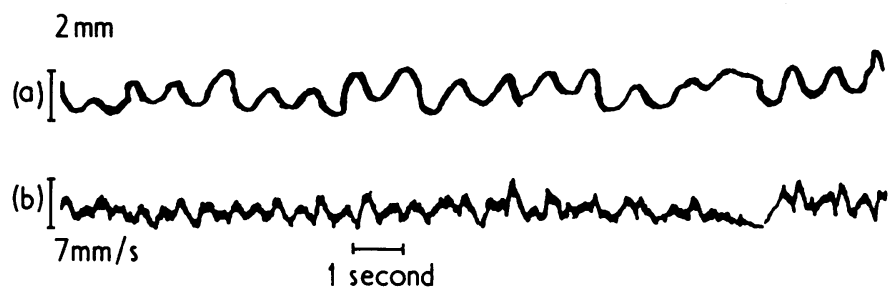

FIG 2-Traces of fetal respiratory movement showing (a) displacement and (b) velocity of fetal chest.

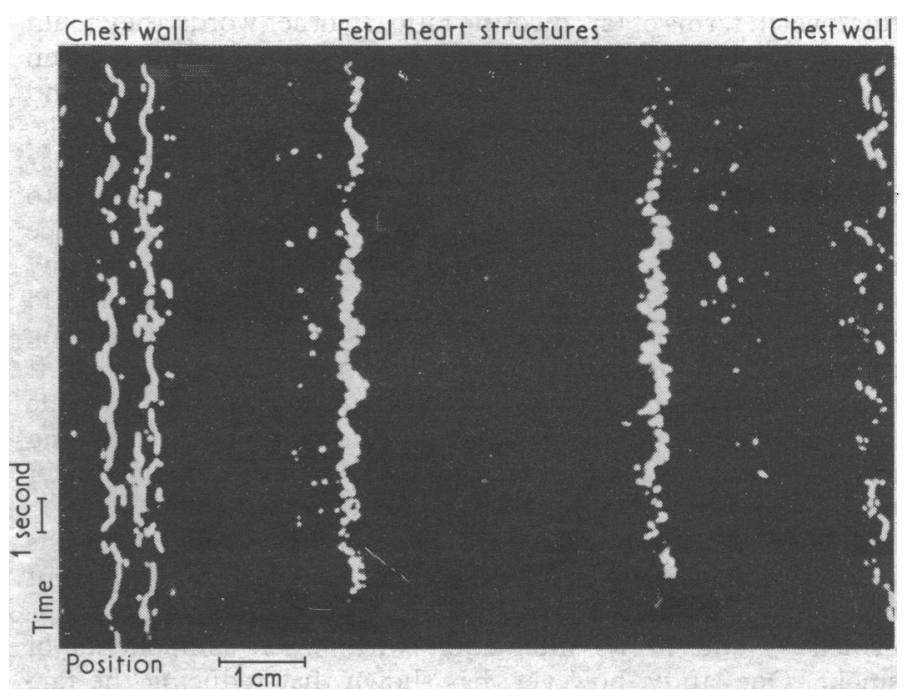

FIG 3-Time-position image of respiratory movement of 36-week-old fetus.

The effect of maternal respiration is seen on the anterior abdominal wall and posterior uterine wall. Fig 2 shows a tracing of fetal respiratory movement with respect to displacement and velocity of the fetal chest wall. Fig 3 shows the respiratory movement of a 36-week-old fetus.

\section{Discussion}

By imaging both walls of the fetal chest simultaneously the nature of any chest movement may be unambiguously defined. This can be achieved using the time-position mode presentation on a storage oscilloscope. Permanent recording of this information either by photography or fibreoptic recorders is expensive, and the relatively inexpensive chart recordings of a single target echo can provide the recording of activity. The 
nature of this activity is verified from the time-position information at the time of recording. The simultaneous recording of velocity with position of the chest wall gives further help in analysing fetal respiratory movement.

This work was supported by grants from the New Zealand Medical Research Council and the Canterbury Medical Research Foundation.

\section{References}

${ }^{1}$ Boddy, K, and Robinson, J S, Lancet, 1971, 2, 1231.

2 Boddy, K, and Dawes, G S, British Medical Bulletin, 1975, 31, 3.

${ }^{3}$ Farman, D J, Thomas, G, and Blackwell, R J, Ultrasound in Medicine and Biology, 1975, 2, 31 .

4 Tremewan, R N, Tait, J J, and Aickin, D R, New Zealand Medical fournal, 1975, 81, 436 .

\title{
Follow-up study of small-for-dates babies
}

\author{
ROBIN FANCOURT，STUART CAMPBELL， DAVID HARVEY，A P NORMAN
}

British Medical fournal, 1976, 1, 1435-1437

\section{Summary}

A group of small-for-dates full-term babies whose intrauterine growth was followed by serial ultrasonic cephalometry were examined at a mean age of 4 years. Those children whose skull growth had begun to slow in utero before 34 weeks' menstrual age were more likely to have a height and weight less than the 10th centile. When the onset of growth failure had occurred before 26 weeks there was a lower developmental quotient at follow-up using the Griffiths extended scales. Prolonged slow growth in utero therefore seems to be followed by slow growth and development after birth.

\section{Introduction}

Small-for-dates babies are more likely to die at birth than normal babies, and follow-up studies show that some of these children continue to grow poorly. ${ }^{1-6}$ They may also have an increased incidence of mental handicap, and a significant number have educational difficulties. ${ }^{7}{ }^{8}$ It has not been possible, however, to predict at birth which small-for-dates babies will continue to grow slowly or have learning difficulties, even if their birthweight is $40^{\circ}$ o under the expected value. ${ }^{3}$

We thought that the intrauterine growth pattern and rate might help in this prediction and we therefore assessed 60 small-for-dates term babies when they reached about 4 years of age. The antenatal growth of all these babies had been followed by serial ultrasonic cephalometry.

\section{Patients}

Records were found of 93 babies who were small for dates at birth and who had had adequate serial cephalometry. Sixty children were traced and seen for follow-up examination. A further 21 children were traced, but could not be seen ( 12 had emigrated, three refused to attend, four had been adopted, and two had died). Three children were excluded as they had a condition which might cause poor growth-major congenital abnormality, chromosomal abnormality, or congenital viral infection. The remainder could not be traced. All but four of the children were Caucasian; all were singleton births.

\footnotetext{
Queen Charlotte's Maternity Hospital and Institute of Obstetrics and Gynaecology, London W6 OXG

ROBIN FANCOURT, MRCP, paediatric research fellow

STUART CAMPBELL, FRCOG, professor of clinical obstetrics and gynaecology

DAVID HARVEY, FRCP, consultant paediatrician

A P NORMAN, MD, FRCP, consultant paediatrician
}

The standards used for classifying the birth weights into centile groups allow for maternal height and weight and the baby's sex. ${ }^{9} \mathrm{~A}$ baby was called small for dates if the birth weight was below the 10th centile. Menstrual age was calculated from the mother's last menstrual period and confirmed by early biparietal diameter measurement (BPD); in five cases, when maternal dates were not certain, the expected date of delivery was calculated from early cephalometry alone. ${ }^{10}$ All babies were born at term-that is, the menstrual age was 37 or more completed weeks. Paediatric examination agreed with the period of gestation in all cases.

Fifty-four of the babies were born at Queen Charlotte's Maternity Hospital; the remaining six were born at five different hospitals in the UK. All had standard neonatal care, including resuscitation, early feeding, attention to temperature control, and the detection of hypoglycaemia.

\section{ULTRASOUND INFORMATION}

In most cases the mother had been referred to the ultrasound department because the fetus was thought to be small on abdominal palpation. Serial measurements of BPD were begun on all patients before 30 weeks' menstrual age and were continued to within two weeks of delivery. The technique of cephalometry has been described, ${ }^{11}$ and all the measurements were made by SC. The reproducibility of measurements is high (the $95^{\circ}{ }_{0}$ confidence limits for weekly growth

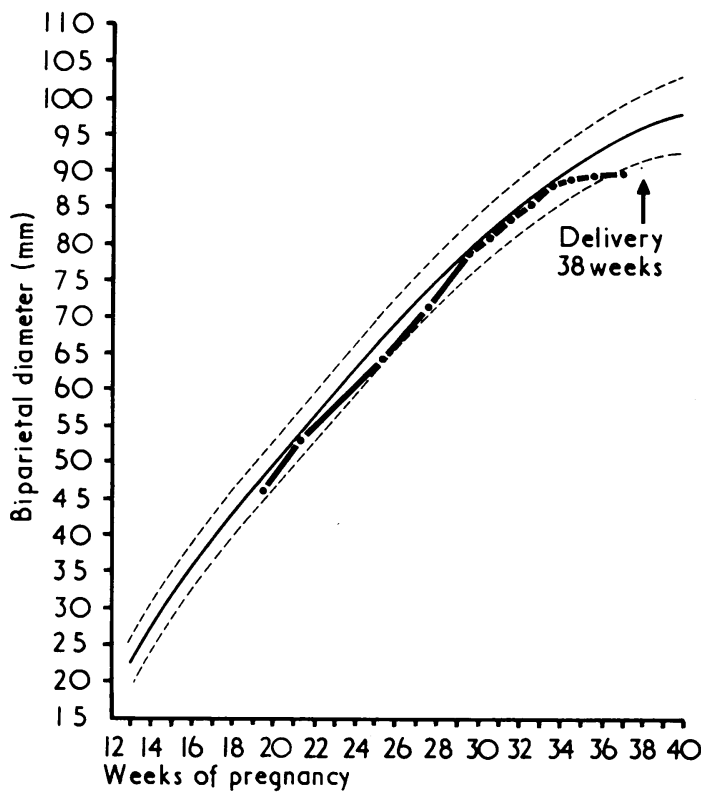

FIG 1-Cephalometry growth chart showing growth of fetal biparietal diameter with late slowing. Labour was induced at 38 weeks because of pre-eclampsia; emergency caesarean section was performed for fetal distress and the Apgar score was two at one minute. Birth weight was $2450 \mathrm{~g}$. 